\title{
Modelling silicon carbide based power electronics in electric vehicles as a study of the implementation of semiconductor devices using Dymola
}

\author{
Leonard Janczyk $^{1} \quad$ Yoshihisa Nishigori $^{2} \quad$ Yasuo Kanehira $^{3}$ \\ ${ }^{1}$ Dassault Systèmes, Germany, leonard.janczyk@3ds.com \\ ${ }^{2}$ ROHM Co., Ltd., Japan, yoshihisa.nishigorierohm.dsn.co.jp \\ ${ }^{3}$ Dassault Systèmes, Japan, yasuo. kanehira@3ds . com
}

\begin{abstract}
In a joint effort, Dassault Systèmes and Rohm Semiconductor demonstrate how the introduction of silicon carbide $(\mathrm{SiC})$ as a base material in power electronics improves the energy efficiency of a typical electric vehicle. As an application example simulation models of an electric drive and an electric vehicle are chosen.
\end{abstract}

Keywords: $\quad$ Power electronics, inverter, electric vehicles, Silicon carbide semiconductor, Dymola, Electrified Powertrains Library

\section{Introduction}

With the evolution of electric vehicles, electric powertrains with electric motors powered by a battery are increasingly becoming part of vehicles as well as of the onboard power supply system. In the industry market, renewable energies have different specifications and must be converted to fit to existing power networks. Additionally, in many cases, renewable energy system need a battery to operate continuously (Nakamura, 2015).

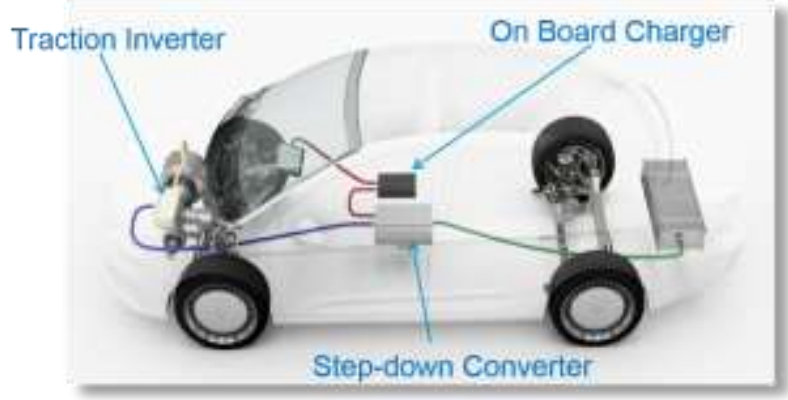

Figure 1 Concept drawing with power electronics linking the plug-in-charger (red), the DC battery circuit (green) the electric motor (blue).
In the mentioned applications, an electric system needs to link circuits with different voltage levels or circuits with alternating current (AC) and direct current (DC). This connection is facilitated by transformers or power electronics. Power electronics are often used in systems where dimensions and weight are important, such as electric vehicles (EV). For example, power electronics are required to link the battery pack, the electric machine and plug-in cable chargers, as illustrated in Figure 1.

Dassault Systèmes and Rohm Semiconductor are jointly investigating the use of system simulation for these cases, which utilizes semiconductor devices in a system simulation environment like Dymola.

After providing background information on power electronics and the advantages of $\mathrm{SiC}$ in chapter 2 , the inverter models from the power electronics package in the Electrified Powertrains Library (EPTL) are introduced in chapter 3.

The thermal-electric modeling and calibration of an inverter module are explained in chapter 4.

In chapter 5 , the inverter model is used in a system model of an electric drive to analyze the effect of the new power electronics material on the system electric efficiency and cooling requirements.

After converting the electric drive system model into a multi-dimensional table model in order to improve simulation speed, the improvement in energy efficiency and vehicle range is shown by a simulation of an electric vehicle. 


\section{Background}

\subsection{Silicon carbide (SiC)}

Like most semiconductors, power electronics use silicon as a base material. Other types of materials include germanium and gallium nitride. A newcomer to this list is silicon carbide (SiC). Its material properties make it ideal for usage in power electronics: it is among the most mechanically robust materials (after carbon diamonds) and is able to withstand operating temperatures up to $200^{\circ} \mathrm{C}$. Its specific thermal conductivity is five times higher than that of silicon, which facilitates the dissipation of electric loss power. Finally, the specific electric resistance is lower than traditional semiconductor materials.

$\mathrm{SiC}$ is a compound semiconductor which consists of silicon ( $\mathrm{Si}$ ) and carbon (C). It has superior performance compared to $\mathrm{Si}$, with the breakdown electric field being ten times stronger and the band gap three times wider.

\section{2 $\mathrm{SiC}$ characteristics in power electronics devices}

Since the breakdown electric field of $\mathrm{SiC}$ is a magnitude stronger than $\mathrm{Si}$, it is possible to build high-voltage devices with maximum operation voltages ranging from $600 \mathrm{~V}$ to a few thousand Volts with high doping density and thin drift layer. As most of the resistance of a highvoltage power device is in the drift layer, $\mathrm{SiC}$ can realize a high breakdown voltage device with extremely low on-resistance per unit area. In theory, the drift layer resistance per area can be reduced by a factor of 300 compared to $\mathrm{Si}$ for the same breakdown voltage (Nagano, 2018).

Minority carrier devices, i. e. bipolar devices such as IGBTs (Insulated Gate Bipolar Transistor) have been mainly used for $\mathrm{Si}$ in order to improve the increase in on-resistance accompanying high breakdown voltage. It has a problem on larger switching loss, however, the switching frequency is limited due to the dissipated heat generated by the electric loss power.

With $\mathrm{SiC}$, a majority carrier device such as Schottky Barrier Diode (SBD) and MOSFET, which is a highspeed device structure, can be manufactured with high breakdown voltage. The device simultaneously enables three characteristics for power transistors: high breakdown voltage, low on-resistance, and high speed. Moreover, the wider band gap than $\mathrm{Si}$ allows power devices that can operate at very high temperatures (Tanaka, 2018) and (Ogawauchi, 2018).

Historically, Rohm financed the development of SiC devices and established an integrated production ranging from pulling wafer ingots to packaging and test. Rohm is starting to offer high-quality $\mathrm{SiC}$ devices, SBDs, and modules.

The adoption in industrial high-voltage power supplies and onboard electric vehicles chargers has started (Nakamura, 2015). Rohm is an official technology partner of the Venturi Formula E team and provides $\mathrm{SiC}$ devices for motor drive inverters.

In this way, $\mathrm{SiC}$ is a key state-of-the-art device to increase the efficiency of electric power systems around the world.

\section{Electrified Powertrains Library}

\subsection{Overview}

The Electrified Powertrains Library (EPTL) contains models covering the key components of an electric drive system in different levels of detail, i.e. physical, switched, averaged and energy-based. The key components are electric machines and inverters with their respective controllers.

\subsection{Power electronics package}

The power electronics package contains models to describe switching electronic devices required in the context of e.g. electric drive modeling.

It contains the semiconductor switches at the heart of the power electronic devices as well as power electronics devices such as inverters and converters.

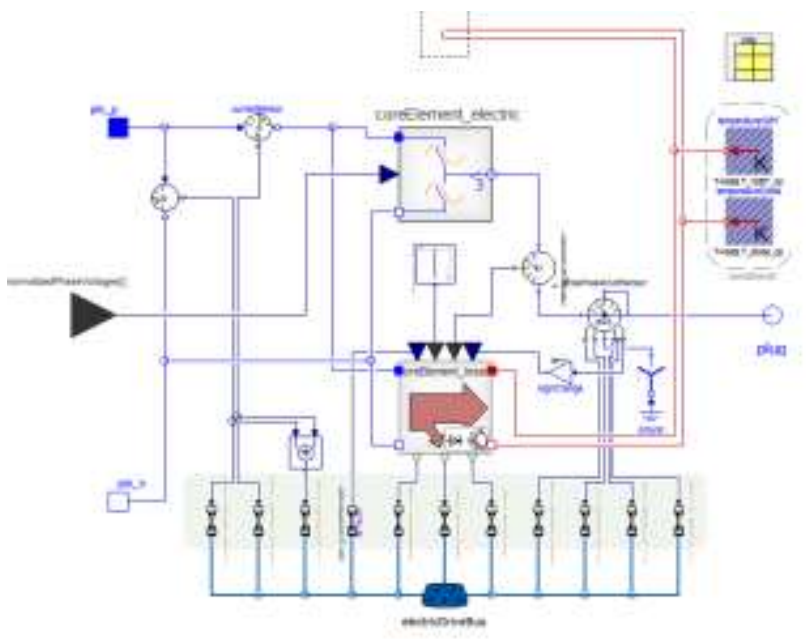

Figure 2 Electrical and loss model of an inverter.

In this context, inverters are of special interest, as their functionality allows to bridge AC and DC electric circuits. Inverter models are available in several levels of detail:

- idealized averaged electric models,

- averaged electric models with losses,

- idealized switching electrical models,

- switching electrical models with losses,

\subsubsection{Electrical Model}

Among the model variants available in the EPTL, the electrical behavior is modelled by the averaged model with constant efficiency in order to increase the simulation speed in large scale system models in later stages.

The input load signal is the desired three-phase voltage. 
The active current that has to be drawn from the battery determined by recording the phase currents and phase shift. For the active current, the Clarke transformation is subsequently applied on the threephase currents for converting the AC currents into a space vector with real and imaginary part.

Assuming a constant efficiency $\eta$, the relationship between the current on $\mathrm{AC}$ and $\mathrm{DC}$ side of the inverter is modelled by the following equation:

$$
I_{D C}=I_{A C} \cdot\left(1+\frac{1-\eta}{\eta}\right)
$$

Major differences between the averaged and the switching electrical models include that the averaged model is an approximation of a switched inverter and does not describe the harmonics of the AC electric signal apart from the fundamental wave. Hence, the behavior is different to a model of a switched inverter as soon as the load is not $100 \%$ sinusoidal anymore. For example, switched inverter models coupled detailed with the respective loss models can be used to find a trade-off between current ripple and inverter losses.

A detailed description of the electric behavior models for MOSFET, IGBT and switches can be found in (Denz, 2014). The mentioned publication comprises also a validation of the EPTL models using electric measurement data.

\subsubsection{Losses Model}

The loss model computes the power losses incurred by the following effects:

- Conduction losses of the diode with regards to forward voltage $V_{f 0}$ taken from the datasheet $P_{\text {cond,diode }}=\left(\frac{1}{2 \pi}-m \cdot \cos \left(\frac{\phi}{8}\right)\right) \cdot V_{f 0} \cdot \sqrt{2} \cdot I$

- Conduction losses of the switching element with regards to drain-source voltage $V_{d s 0}$, drain current and device temperature:

$$
P_{\text {cond,switch }}=\left(\frac{1}{2 \pi}+\frac{m \cdot \cos (\phi)}{8}\right) \cdot V_{d s 0} \cdot \sqrt{2} \cdot I
$$

- Reverse recovery of the diode with regards to forward voltage forward current, device temperature and forward voltage:

$$
P_{\text {loss }, R R}=n_{s} \cdot E_{r r} \cdot \frac{\sqrt{2}}{\pi} \cdot\left(\frac{V}{V_{r e f}}\right)^{K_{v}}
$$

- Loss energy per switching operation with regards to current, device temperature and voltage to switch:

$$
P_{\text {switching }}=n_{s} \cdot\left(E_{\text {on }}+E_{\text {off }}\right) \cdot \frac{\sqrt{2}}{\pi} \cdot\left(\frac{V}{V_{\text {ref }}}\right)^{K_{v}}
$$

In this context $m$ is the modulation index, $I$ the load current, $n_{s}$ the number of switches, $V_{\text {ref }}$ the reference voltage for the datasheet parameters, $K_{v}$ a coefficient for accounting the non-linear influence of the normalized voltage on the losses.

Forward voltage, drain-source voltage as well as the energies for on/off switching and reverse-recovery need to be entered as parameter table as specified in the datasheet, as given in the Appendix.

The power losses are turned into heat flow and can be connected to the thermal model in order to predict the device temperature.

\subsubsection{Thermal Model}

Along with the model describing the electrical behavior and the loss generation, shown in Figure 2, a thermal representation of the respective inverter is comprised. The diode and the MOSFET are modelled as so called Foster elements. The Foster element is an electric equivalent circuit model which describes the transient thermal behavior of the device as concatenated $\mathrm{RC}$ circuits. In this context the thermal mass is treaded as capacitor element and the thermal conductance as resistor element. The thermal conductance from junction to the casing of the module's switch and diode is given by the datasheet and multiplied by the number of elements, in that application with the number of the module's switches, which is six for this device.

\section{Modelling and calibration of an Silicon carbide based inverter module}

\subsection{Topology}

The inverter model is based on the half bridge module BSM120D12P2C005 by Rohm Semiconductor (Rohm, 2016) with the characteristics as listed in Table 1.

Table 1. Characteristics of the used device (SiC) and a Silicon $(\mathrm{Si})$ based benchmark device.

\begin{tabular}{|l|c|c|}
\hline \multicolumn{1}{|c|}{ Category } & Device & Benchmark \\
\hline Technology & $\mathrm{SiC}$ & $\mathrm{Si}$ \\
\hline Type & MOSFET & IGBT \\
\hline Maximum Voltage & $1200 \mathrm{~V}$ & $1700 \mathrm{~V}$ \\
\hline Voltage Drain-Source & $600 \mathrm{~V}$ & $900 \mathrm{~V}$ \\
\hline Maximum Current & $120 \mathrm{~A}$ & $150 \mathrm{~A}$ \\
\hline Operating Temperature & $150{ }^{\circ} \mathrm{C}$ & $80{ }^{\circ} \mathrm{C}$ \\
\hline Number of switches & 6 & 6 \\
\hline Voltage coefficient $K_{v}$ & 1.35 & 1.35 \\
\hline
\end{tabular}

It consists of a MOSFET and a Schottky Barrier Diode (SBD), both based on silicon carbide.

The module is modelled using an averaged electric model with losses and a thermal model

\subsection{Calibration of the power module}

Additionally to the scalar parameters as shown in Table 1, the electric model of the diode includes the multi-dimensional relationship of source current and source drain voltage with regards to the operating temperature of the device. 
Moreover, the calculation of the dissipated heat losses requires to enter the loss energy per switching operation as well as the recovered loss energies with regards to drain current and operation temperature.

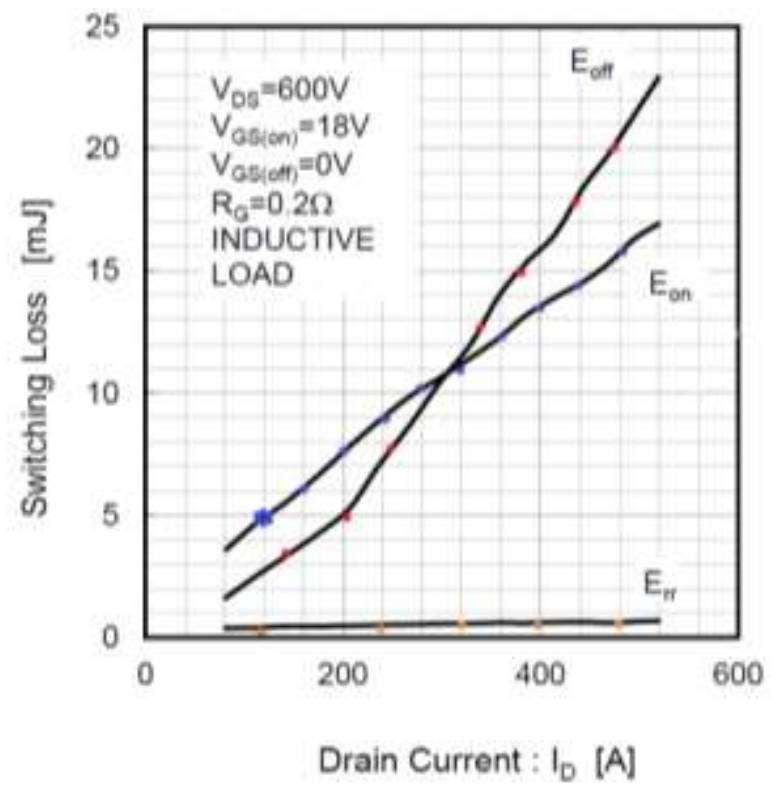

Figure 3. Sampling the characteristic curve of the used $\mathrm{SiC}$ device for switching losses when operating at $25^{\circ} \mathrm{C}$.

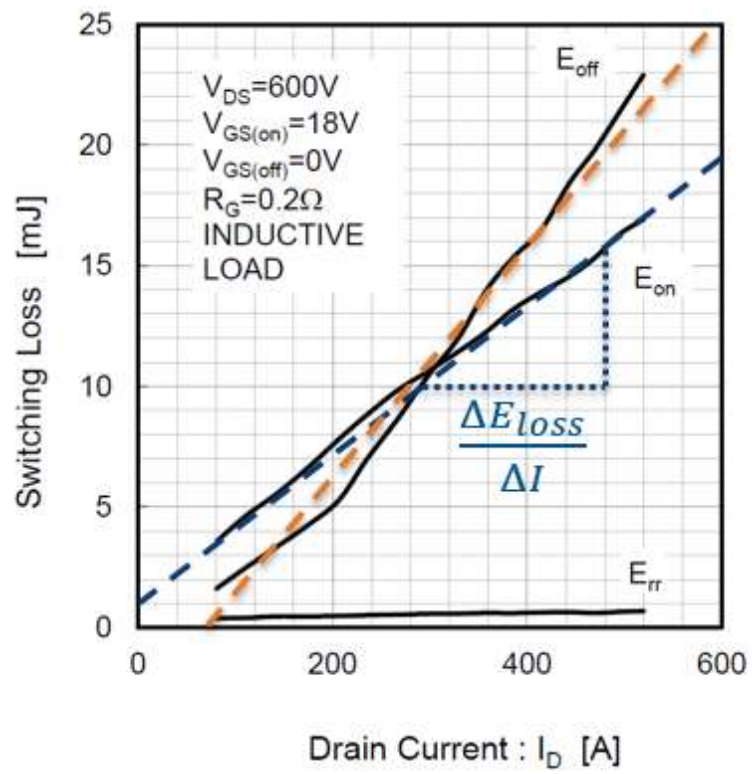

Figure 4. Linearizing the characteristic curve of the used $\mathrm{SiC}$ device for switching losses when operating at $25^{\circ} \mathrm{C}$.

There are two options for calibrating the $\mathrm{SiC}$ device in the EPTL:

(1) Table Based: Either by sampling the characteristic curves given for the respective device, as indicated for example in Figure 3. The recorded data set is interfacing the Modelica model via the NDTable class. The output for given operating load and conditions is generated by performing a multidimensional interpolation in the data set.
(2) Linear equation: When the device characteristics feature sufficiently linear dependencies, the curve can be captured by linear equations within a confined area of operation as sketched in Figure 4.

With the switch-off loss energy curve with regards to drain current displays discontinuities, especially at 200 amperes, the table based method is chosen for modelling the losses.

The class NDTable for is implemented as described by (Schmitt et al, 2015) for an example for the forward characteristic of a Si-based diode.

\subsection{Testbench simulation}

In order to assess the impact of the increased efficiency the inverter is simulated as part of an electric drive system model as shown in Figure 5.

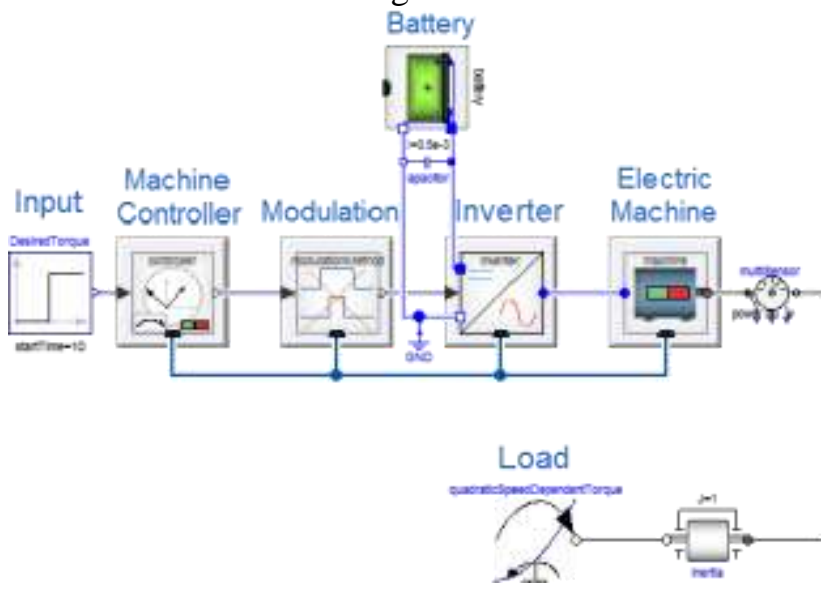

Figure 5 Simulation set up: Electric drive system including electric and loss model of the inverter comprising the power electronics.

The electric drive consists of five components: the electric machine with its machine controller, the inverter with modulation and the battery pack. The impedance effects of the cables of the high-voltage circuit as well as additional electric consumers of auxiliary devices are neglected in this setup.

Table 2 Simulation starting values and boundary conditions for the simulation.

\begin{tabular}{|l|l|}
\hline Variable [Unit] & Value \\
\hline Operating Temperature $\left[{ }^{\circ} \mathrm{C}\right]$ & 80 \\
\hline Switching frequency $[\mathrm{kHz}]$ & 25 \\
\hline Modulation harmonic [type] & sinus \\
\hline Electric machine type [type] & PSM \\
\hline Nominal machine frequency [Hz] & 195 \\
\hline Nominal torque [Nm] & 122 \\
\hline Nominal phase RMS voltage [V] & 114 \\
\hline Nominal RMS current per phase [A] & 170 \\
\hline Electric machine power [kW] & 50 \\
\hline Desired Torque as input [Nm] & +10 \\
\hline Load Torque [Nm] & -10 \\
\hline Nominal machine speed [rpm] & 1000 \\
\hline
\end{tabular}


The electric machine is a $50 \mathrm{~kW}$ three-phase permanent magnet synchronous machine (PSM) with three pairs of poles. The corresponding machine controller has the target torque as input and features field-weakening control and the maximum-torque-perampere control.

With $25 \mathrm{kHz}$, a comparably high value has been chosen as switching frequency in order to illustrate the contrast in terms of dissipated loss power.

The overall boundary conditions of the simulation are laid down in Table 2.

The simulation in Figure 6 illustrates that lower switching energies result into lower heat loss power, hence a lower power consumption on the DC power side.

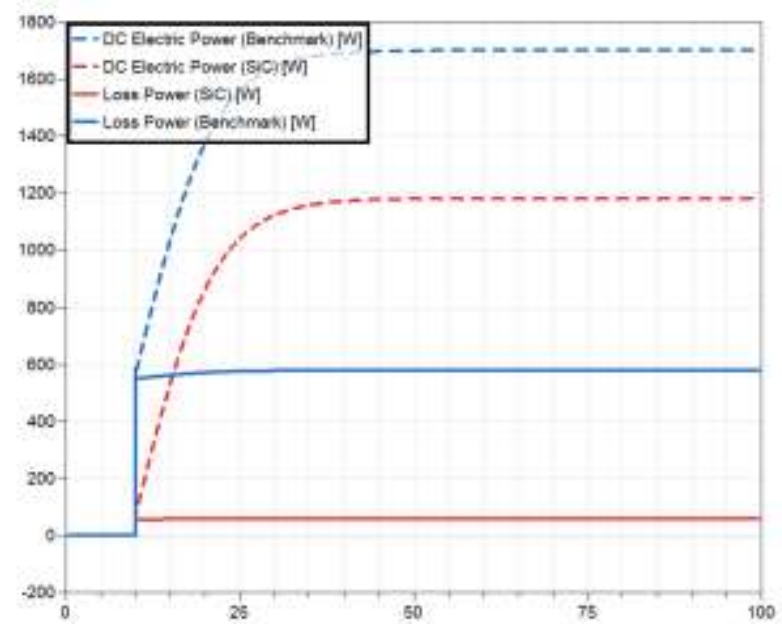

Figure 6 Comparison of DC load power and loss power between Si-based benchmark device (blue) and SiC-based device (red) for the first 100 seconds simulation time.

With the DC power load reduced significantly, the battery experiences a lower draining for providing a similar level of AC output. The battery charging state (SOC, that is the state-of-charge) therefor remains at a higher level.

\section{Simulation and discussion}

\subsection{Water-cooled electric drive system}

In order to assess the implication of the reduced loss power as calculated in chapter 4.3 , the electric testbench component models are complemented by the respective thermal representation.

The use case as illustrated in Figure 7 consists of a permanent magnet synchronous machine which is water-cooled with the used liquid cooling media type being water/ethylene-glycol (50:50), as given in the FluidHeatFlow package in the Thermal library of the Modelica Standard Library 3.2.2. It represents a typical automotive setup with an external pump causing a volume flow through the inverter first and the machine subsequently. The inlet and outlet of the cooling cycle are modelled by the class Sources. Ambient. The component pump is an instance of the VolumeFlow class in the same package.

As modelling complexity increased significantly with the liquid cooling cycle, the battery was replaced by voltage source.

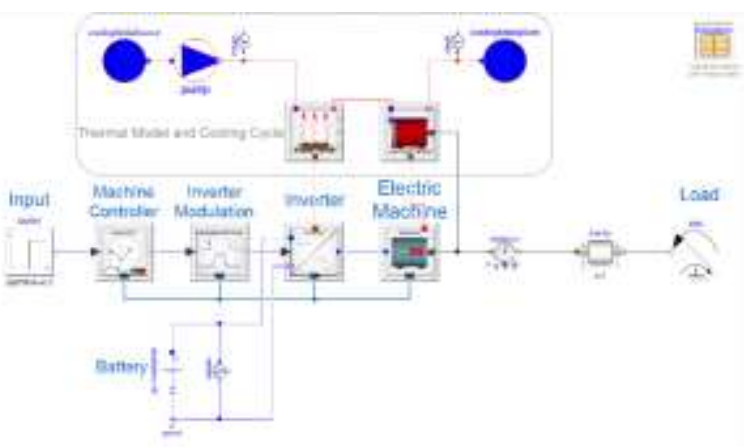

Figure 7 Simulation set up: Water-cooled electric drive system including thermal-electric models of inverter and electric machine.

The resulting reduction of the load for the cooling cycle is assessed by a simulation with the configuration as laid down in Table 3.

Table 3 Simulation starting values and boundary conditions for the simulation.

\begin{tabular}{|l|l|}
\hline Variable [Unit] & Value \\
\hline Inlet temperature coolant $\left[{ }^{\circ} \mathrm{C}\right]$ & 65 \\
\hline Volume flow $[1 /$ min] & 6.0 \\
\hline Operating Temperature $\left[{ }^{\circ} \mathrm{C}\right]$ & transient \\
\hline Switching frequency $[\mathrm{kHz}]$ & 25 \\
\hline Modulation harmonic $[\mathrm{type}]$ & sinus \\
\hline Electric machine type $[\mathrm{type}]$ & $\mathrm{PSM}$ \\
\hline Electric machine power $[\mathrm{kW}]$ & 50 \\
\hline Desired Torque (Input) $[\mathrm{Nm}]$ & +122 \\
\hline Load Torque $[\mathrm{Nm}]$ & -122 \\
\hline Nominal machine speed $[\mathrm{rpm}]$ & 3000 \\
\hline
\end{tabular}

In Figure 8 is result of the testbench simulation is shown. With the generated heat losses reduced, the coolant experiences a significantly lower temperature increase.

With using a cooling cycle with liquid cooling, the indicator by choice is the temperature of the cooling medium. The coolant's temperature is increased by the dissipated heat loss power. The interfacing thermal conductance model is provided by Foster circuit parameters. 


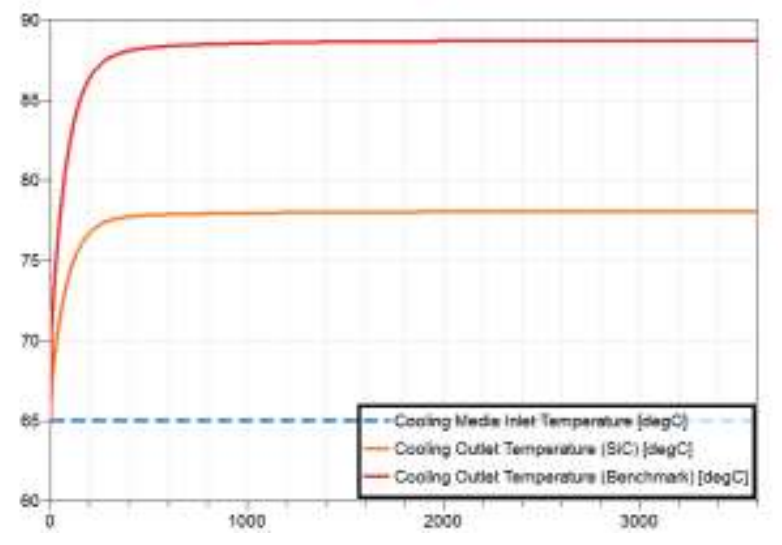

Figure 8 Simulation result: cooling medium temperature at the inlet and the outlet of the cooling cycle.

\subsection{Electric vehicle simulation}

The vehicle simulation package allows setting up example use cases for electric drives in different characteristics, providing an expandable and configurable infrastructure as well as all required components from environment to operational control models.

Hence characteristic maps are created for a specific supply voltage and specific temperatures. These values must be defined before the map generation process is started. For this purpose the boundary conditions as described in chapter 4.3 are chosen assuming that the inverter are operated in thermal equilibrium by using the cooling cycle as defined in chapter 5.1.

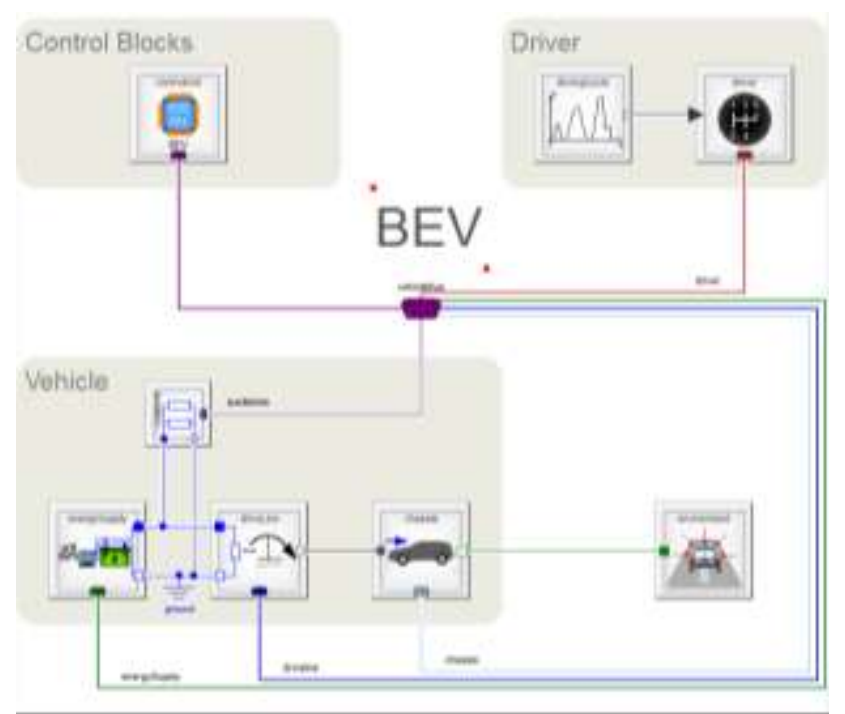

Figure 9 Electric Vehicle Simulation Testbench

With the battery being the primary source of energy, the electric powertrain as shown in Figure 10, the driving range increases significantly according to the simulation displayed in Figure 11.

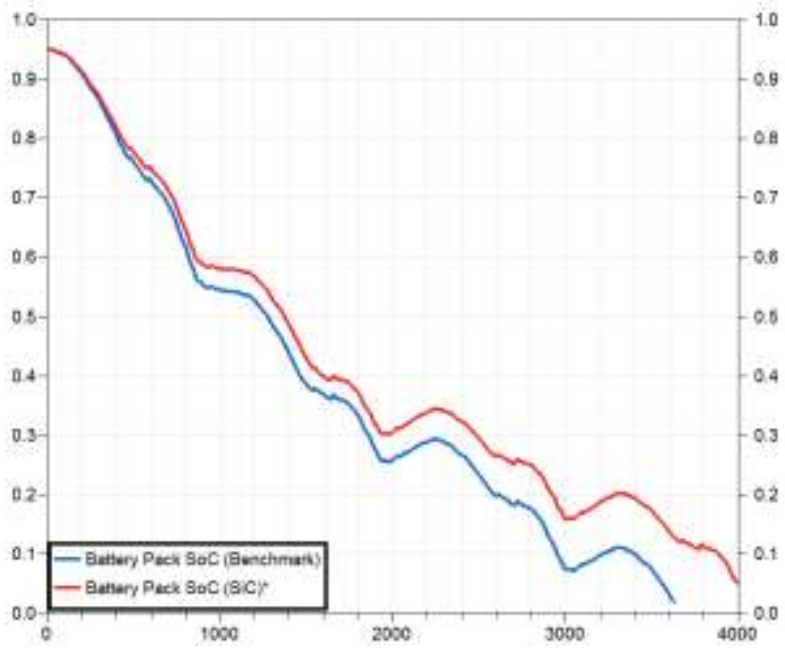

Figure 10 Charging state (SOC) of the EV traction battery when adopting the driving profile "Artemis Motorway".

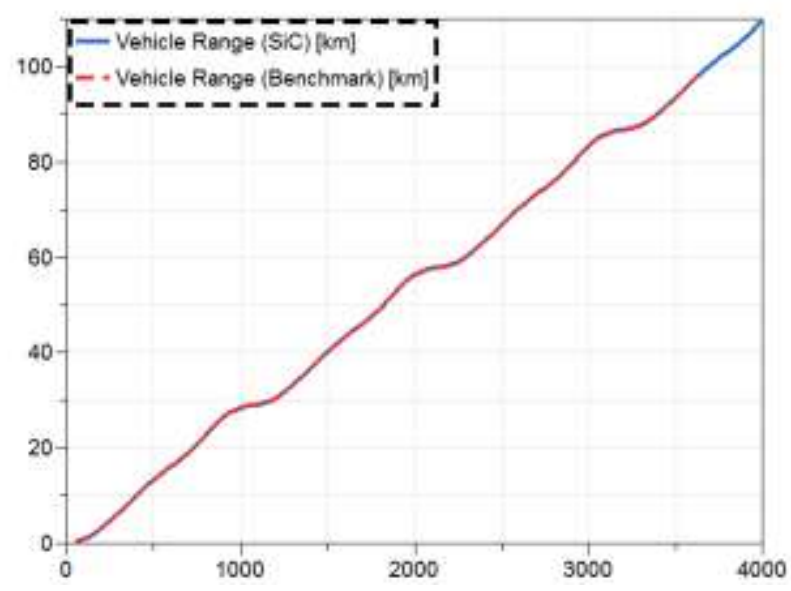

Figure 11 Maximum EV driving range when adopting the driving profile "Artemis Motorway".

\section{Outlook}

Tuning, increased accuracy in the simulation environment still be necessary, but it was already possible to demonstrate the improvement generated by device replacement just with high-level simulation.

Application of $\mathrm{SiC}$ in DC/DC converters is currently increasing, and with improvements in the relationship of performance and cost, the authors are confident that the application of $\mathrm{SiC}$ will expand. 


\section{References}

Patrick Denz, Thomas Schmitt, Markus Andres. Behavioral Modeling of Power Semiconductors in Modelica. Proceedings of the $10^{\text {th }}$ International Modelica Conference, Lund, Sweden, 2014. doi:10.3384/ECP14096343

Rohm Co., Ltd. SiC Power Module BSM120D12P2C005. Data sheet. 2016.09 - Rev C. 2016.

Thomas Schmitt, Markus Andres, Stephan Ziegler, Stephan Diehl. A Novel Proposal on how to Parameterize Models in Dymola Utilizing External Files under Consideration of a Subsequent Model Export using the Functional Mock-Up Interface. Proceedings of the $11^{\text {th }}$ International Modelica Conference, Versailles, France, 2015 doi:10.3384/ecp1511823

T. Nakamura, Y. Nakano, T. Hanada. Advanced SiC Power Devices and Their Prospects. 4_S10_5, VOL. 3, IEE-Japan Industry Applications Society Conference, Japan, 2015.

K. Tanaka, S. Kyogoku, R. Iijima, S. Harada. Impact of the trench bottom shielding region on switching characteristics in SiC Double-trench MOSFETs. 4-010 Annual Meeting of the IEEJ 2018.

T. Nagano, K. Matsubara, H. Takubo, A. Toba. Suppression of Surge Voltage by Active Gate Driving for SiCMOSFETs. 4-017, Annual Meeting of the IEEJ 2018.

Y. Ogawauchi, K. Nakahara "A Study on High-speed Gate Drive Circuit Using Hybrid Current/Voltage Source ofor SiC-MOSFET" 4-018 Annual Meeting of the IEEJ 2018

\section{Appendix}

\section{Rohm BSM120D12P2C005 parameters}

\section{Output Characteristics}

MOSFET drain-source voltage with regards to drain current and device temperature, measured in Volt.

\begin{tabular}{|l|c|c|c|}
\hline ID [A] & $25^{\circ} \mathrm{C}$ & $125^{\circ} \mathrm{C}$ & $150^{\circ} \mathrm{C}$ \\
\hline 40 & 0.6507 & 0.9771 & 1.105 \\
\hline 80 & 1.3582 & 1.9828 & 2.224 \\
\hline 120 & 2.1082 & 3.0735 & 3.457 \\
\hline 160 & 2.9151 & 4.2496 & 4.818 \\
\hline 200 & 3.8213 & 5.6101 & 6.377 \\
\hline 240 & 4.8 & 7.1269 & 8.500 \\
\hline
\end{tabular}

\section{Diode Forward Characteristics}

Source-drain voltage with regards to source current and device temperature, measured in Volt.

\begin{tabular}{|c|c|c|c|}
\hline $\mathrm{I}[\mathrm{A}]$ & $25^{\circ} \mathrm{C}$ & $125^{\circ} \mathrm{C}$ & $150^{\circ} \mathrm{C}$ \\
\hline 30 & 0.53 & 0.80 & 0.83 \\
\hline 40 & 0.70 & 0.92 & 0.95 \\
\hline 60 & 1.00 & 1.20 & 1.75 \\
\hline 80 & 1.13 & 1.30 & 1.40 \\
\hline 120 & 1.35 & 1.65 & 1.80 \\
\hline 160 & 1.55 & 2.00 & 2.20 \\
\hline 200 & 1.75 & 2.40 & 2.60 \\
\hline 240 & 1.97 & 2.75 & 3.05 \\
\hline
\end{tabular}

\section{Switch-on energy}

Loss energy per switch-on operation with regards to load current and device temperature, measured in Joule.

\begin{tabular}{|l|r|l|}
\hline $\mathrm{I}[\mathrm{A}]$ & $25^{\circ} \mathrm{C}$ & $125^{\circ} \mathrm{C}$ \\
\hline 20 & $0.8000 \mathrm{e}-3$ & $1.0000 \mathrm{e}-3$ \\
\hline 40 & $1.4946 \mathrm{e}-3$ & $1.3441 \mathrm{e}-3$ \\
\hline 80 & $2.7321 \mathrm{e}-3$ & $2.2566 \mathrm{e}-3$ \\
\hline 120 & $3.9696 \mathrm{e}-3$ & $3.1816 \mathrm{e}-3$ \\
\hline 160 & $5.2071 \mathrm{e}-3$ & $4.0440 \mathrm{e}-3$ \\
\hline 200 & $6.5571 \mathrm{e}-3$ & $5.0066 \mathrm{e}-3$ \\
\hline 240 & $8.2607 \mathrm{e}-3$ & $5.9441 \mathrm{e}-3$ \\
\hline
\end{tabular}

\section{Switch-off energy}

Loss energy per switch-off operation with regards to load current and device temperature, measured in Joule.

\begin{tabular}{|l|r|l|}
\hline $\mathrm{I}[\mathrm{A}]$ & $25^{\circ} \mathrm{C}$ & $125^{\circ} \mathrm{C}$ \\
\hline 20 & $0.3000 \mathrm{e}-3$ & $0.3000 \mathrm{e}-3$ \\
\hline 40 & $0.4982 \mathrm{e}-3$ & $0.5809 \mathrm{e}-3$ \\
\hline 80 & $1.1732 \mathrm{e}-3$ & $1.2807 \mathrm{e}-3$ \\
\hline 120 & $1.9445 \mathrm{e}-3$ & $2.1932 \mathrm{e}-3$ \\
\hline 160 & $2.8125 \mathrm{e}-3$ & $3.1432 \mathrm{e}-3$ \\
\hline 200 & $3.8893 \mathrm{e}-3$ & $4.3435 \mathrm{e}-3$ \\
\hline 240 & $5.0143 \mathrm{e}-3$ & $5.6813 \mathrm{e}-3$ \\
\hline
\end{tabular}

\section{Reverse Recovery}

Reverse recovery energy per switching operation with regards to load current and device temperature, measured in Joule.

\begin{tabular}{|l|c|c|}
\hline $\mathrm{I}[\mathrm{A}]$ & $25^{\circ} \mathrm{C}$ & $125^{\circ} \mathrm{C}$ \\
\hline 20 & $0.0482 \mathrm{e}-3$ & $0.0934 \mathrm{e}-3$ \\
\hline 40 & $0.0321 \mathrm{e}-3$ & $0.0801 \mathrm{e}-3$ \\
\hline 80 & $0.0161 \mathrm{e}-3$ & $0.0792 \mathrm{e}-3$ \\
\hline 120 & $0.0161 \mathrm{e}-3$ & $0.0659 \mathrm{e}-3$ \\
\hline 160 & $0.0161 \mathrm{e}-3$ & $0.0300 \mathrm{e}-3$ \\
\hline 200 & $0.0161 \mathrm{e}-3$ & $0.0300 \mathrm{e}-3$ \\
\hline 240 & $0.0161 \mathrm{e}-3$ & $0.0300 \mathrm{e}-3$ \\
\hline
\end{tabular}

\section{Silicon benchmark device parameters}

\section{Output Characteristics}

IGBT collector-emitter voltage with regards to collector current and device temperature, measured in Volt.

\begin{tabular}{|l|c|l|l|}
\hline $\mathrm{I}[\mathrm{A}]$ & $25^{\circ} \mathrm{C}$ & $125^{\circ} \mathrm{C}$ & $150^{\circ} \mathrm{C}$ \\
\hline 40 & 1.31 & 1.34 & 1.33 \\
\hline 80 & 1.56 & 1.75 & 1.78 \\
\hline 120 & 1.83 & 2.1 & 2.18 \\
\hline 160 & 2.04 & 2.43 & 2.54 \\
\hline 200 & 2.25 & 2.76 & 2.92 \\
\hline 240 & 2.47 & 3.1 & 3.31 \\
\hline
\end{tabular}




\section{Diode Forward Characteristics}

Drain-source voltage with regards to source current and device temperature, measured in Volt.

\begin{tabular}{|l|l|l|l|}
\hline $\mathrm{I}$ & $25^{\circ} \mathrm{C}$ & $125^{\circ} \mathrm{C}$ & $150^{\circ} \mathrm{C}$ \\
\hline 40 & 1.17 & 1.06 & 1.06 \\
\hline 80 & 1.39 & 1.35 & 1.35 \\
\hline 120 & 1.54 & 1.55 & 1.56 \\
\hline 160 & 1.68 & 1.74 & 1.77 \\
\hline 200 & 1.81 & 1.9 & 1.95 \\
\hline 240 & 1.92 & 2.06 & 2.12 \\
\hline
\end{tabular}

\section{Switch on Energy}

Loss energy per switch-off operation with regards to load current and device temperature, measured in Joule.

\begin{tabular}{|l|r|c|}
\hline $\mathrm{I}[\mathrm{A}]$ & $125^{\circ} \mathrm{C}$ & $150^{\circ} \mathrm{C}$ \\
\hline 40 & 0.018 & 0.020 \\
\hline 80 & 0.032 & 0.035 \\
\hline 120 & 0.046 & 0.050 \\
\hline 160 & 0.061 & 0.070 \\
\hline 200 & 0.076 & 0.080 \\
\hline 240 & 0.093 & 0.100 \\
\hline
\end{tabular}

\section{Switch off Energy}

Loss energy per switch-off operation with regards to load current and device temperature, measured in Joule.

\begin{tabular}{|l|r|r|}
\hline $\mathrm{I}[\mathrm{A}]$ & $125^{\circ} \mathrm{C}$ & $150^{\circ} \mathrm{C}$ \\
\hline 40 & 0.013 & 0.015 \\
\hline 80 & 0.025 & 0.028 \\
\hline 120 & 0.036 & 0.040 \\
\hline 160 & 0.045 & 0.050 \\
\hline 200 & 0.054 & 0.060 \\
\hline 240 & 0.063 & 0.069 \\
\hline
\end{tabular}

\section{Reverse Recovery}

Reverse recovery energy per switching operation with regards to load current and device temperature, measured in Joule.

\begin{tabular}{|l|r|r|}
\hline $\mathrm{I}[\mathrm{A}]$ & $125^{\circ} \mathrm{C}$ & $150^{\circ} \mathrm{C}$ \\
\hline 40 & 0.019 & 0.023 \\
\hline 80 & 0.028 & 0.031 \\
\hline 120 & 0.034 & 0.038 \\
\hline 160 & 0.040 & 0.044 \\
\hline 200 & 0.045 & 0.048 \\
\hline 240 & 0.048 & 0.051 \\
\hline
\end{tabular}

